one week of treatment with amoxycillin is no more tiring than treatment with placebo. Such a study would have no discriminatory value had it been conducted in patients with an illness inducing fatigue or requiring antibiotic treatment.

Type B subjects and those with an external locus of control more often reported fatigue as a result of treatment. These subjects are more sensitive to the effects of outside factors, such as the intake of drugs, on their lives. Results in psychological tests are good predictors of adherence to and efficacy of treatment. ${ }^{45}$ We have shown that the psychological profile of subjects can either increase or decrease the incidence of side effects. This idea has to be confirmed on a larger scale, but it may be important in the conception of all clinical trials.

1 Scheckler WE, Benett JV. Antibiotic usage in seven community hospitals $\exists A M A$ 1970;123:264-8.

2 Bortner RW. A short rating scale as a potential measure of pattern A behaviour. Journal of Chronic Disease 1969;22:87-91.

Lefcourt HM, ed. Research with the locus of control constructs. Vol 1-3. New York: Academic Press, 1981.

4 Oddson OH, Bass MJ, Donner A, McWhinney IR. Behaviour pattern A and compliance with antihypertensive treatment. Acta Med Scand 1985; 217(suppl):97-101.

5 Crowe McCann C, Goldfarb B, Frisk M, Quera-Salva MA, Meyer P. The role of personality factors and suggestion in placebo effect during mental stress test. Br f Clin Pharmacol 1992;33:107-10.

(Accepted 12 August 1993)

\section{Pneumococcal vaccination after splenectomy: survey of hospital and primary care records}

\author{
Paul Kinnersley, Clare E Wilkinson, \\ Jayashri Srinivasan
}

\section{Department of General Practice, University of Wales College of Medicine, Cardiff CF4 4XN \\ Paul Kinnersley, lecturer}

Clare E Wilkinson, lecturer

Department of Medicine, Llandough Hospital, Penarth, South Glamorgan CF6 1XX

Jayashri Srinivasan, registrar

Correspondence to:

Dr C E Wilkinson,

Department of General

Practice, University of

Wales College of Medicine,

Llanedyrn Health Centre,

The Maelfa, Cardiff

CF3 7PN.

$B M F$ 1993;307:1398-9

Follow up of vaccination statu of patients who had had a splenectomy between 1975 and 1990 in three Cardiff hospitals
Vaccination against pneumococcal infection has been recommended since 1977 to prevent overwhelming infection in patients having splenectomies; it is safe with proved efficacy, and there is consensus on its use. ${ }^{1-4}$ There is international evidence of deficiencies in vaccination policy but no reports from the United Kingdom. ${ }^{5}$ Our study was prompted by the deaths of two young unvaccinated patients from pneumococcal septicaemia in South Glamorgan. We aimed to determine the vaccination rate among patients having splenectomies in Cardiff over 15 years and to facilitate vaccination of those at risk.

\section{Patients, methods, and results}

Patients having splenectomies between 1975 and 1990 were identified from the histology register in three Cardiff hospitals. Of the 737 entries, 557 (76\%)

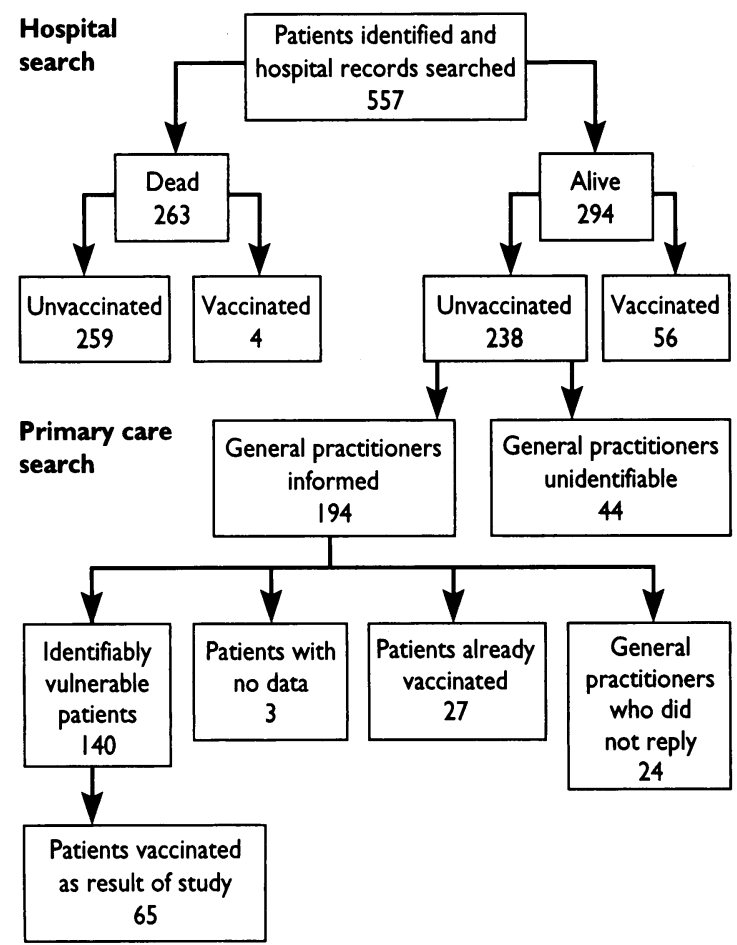

patients' hospital notes were found and searched. The general practitioners of the living, apparently unvaccinated patients were asked to search their primary care records for evidence of subsequent vaccination and to comment on each patient's present health status. All general practitioners were sent an information package about pneumococcal vaccine and were contacted four months later to establish whether this information had led to vaccination.

The hospital records showed that $60(11 \%)$ patients had received pneumococcal vaccination and the primary care records that $27(5 \%)$ patients had received it-a total of $87(16 \%)$ patients (figure). Cause of death was available from the hospital records for 166 of the 263 patients who had died. Thirty seven $(22 \%)$ of them had died of septicaemia or other infections.

Vaccination rates were higher in children $(32 \%$, $25 / 79)$ than in adults $(7 \%, 35 / 477)$ and had improved between 1975-80 (0.7\%, 2/295), 1981-85 (14.2\%, $24 / 169)$, and $1986-90(35.5 \%, 33 / 93)$. Analysis of vaccination rate according to reason for splenectomy showed higher rates in those with benign diseases.

Recording of splenectomy was incomplete in the hospital records, being absent from the operation notes in $19(3 \%)$ cases and from the discharge letter to the general practitioner in $130(23 \%)$. The records of 170 living unvaccinated patients were examined by their general practitioners. Of these, $150(88 \%)$ patients had the splenectomy recorded, with this information being considered "easy" or "very easy" to find in 110 cases. A further 27 patients were found to have been vaccinated by this search. Ninety six $(69 \%)$ of the 140 unvaccinated patients were considered to be in good health. Of those general practitioners responding at follow up, $65(46 \%)$ had vaccinated their patients and $34(24 \%)$ had not.

\section{Comment}

We identified a large group of patients who had had a splenectomy but not been vaccinated. Although vaccination rates have improved over time, it is of concern that such groups probably exist throughout the United Kingdom. Furthermore, the primary care records showed that most of the unvaccinated patients were currently in good health. Clear guidelines for the vaccine were not included in the Department of Health publication Immunisation Against Infectous Diseases until $1992 .{ }^{3}$ Such omissions, coupled with the sporadic nature of cases, may have led to the slow uptake of vaccination.

It is gratifying that 65 previously unprotected patients were vaccinated as part of this study by their general practitioners since they are responsible for the long term care of such patients. Because of the difficulty in diagnosing early sepsis primary care records must mention both the splenectomy and the vaccination status. General practitioners are well 
placed to address the problem of retrospective cohorts of unvaccinated patients. This initiative in South Glamorgan has provoked similar action in other areas (D Periera Gray, personal communication).

This study has implications for surgeons, who should ensure that all patients are vaccinated and that discharge letters are accurate, and for general practitioners, who should ensure adequate follow up and be alert to the possibility of pneumococcal sepsis.

This research was funded by a grant from the Scientific Foundation Board of the Royal College of General Practitioners. We thank Irene Jones and the staff of the records department of the hospital, the Office of Population Censuses and Surveys, Ms Penny Cody, Drs Peter Beck and Haydn Jones, and all the general practitioners who participated in the study.

1 Ammann AJ, Addiego J, Wara DW, Lubin B, Smith WB, Mentzer WC. Polyvalent pneumococcal-polysaccharide immunisation of patients with sickle-cell anemia and patients with splenectomy. $N$ Engl f Med 1977;297: 897-900.

2 United States Department of Health and Human Services Centers for Disease Control. Pneumococcal polysaccharide vaccine. MMWR 1989;38:64-76.

3 Department of Health. Immunisation against infectious diseases. London: HMSO, 1992.

4 Consumers' Association. When to use the new pneumococcal vaccine. Drug Ther Bull 1990;28:31-2.

5 Siddens $M$, Downie J, Wise $K$, O'Reilly $M$. Prophylaxis against postsplenectomy pneumococcal infection. Aust NZ F Surg 1990;60:183-7.

(Accepted 28 September 1993)

\section{Hyponatraemia and catatonic stupor after taking "ecstasy"}

\section{L Maxwell, M I Polkey, J A Henry}

Department of Medicine, Guy's Hospital, London SE1 9RT

D L Maxwell, senior registrar

M I Polkey, registrar

\section{National Poisons Unit,} Guy's Hospital, London SE1 9RT

J A Henry, consultant

physician

Correspondence to:

Dr Henry.

BMF 1993;307:1399

\section{Case reports \\ CASE 1}

The synthetic amphetamine derivative 3,4-methylenedioxymethamphetamine ("ecstasy") may have fatal complications. ${ }^{1}$ We report on two patients who became mute and catatonic for 48 hours after taking this drug.

A 17 year old woman became unwell about four hours after her first ingestion of one and a half tablets of 3,4-methylenedioxymethamphetamine; she had three epileptiform seizures over two hours and was left to "sleep it off." After nine hours she had not recovered and was taken to a local hospital, where she was found to be drowsy and rousable but uncommunicative, with a normal temperature, pulse rate, and blood pressure. She was observed for 12 hours; throughout this period she intermittently opened her eyes but did not respond to or recognise anyone. She was then taken home by her parents, but her condition remained unchanged; she was doubly incontinent and became dehydrated. After 30 hours she was referred for assessment. Her axillary temperature was $37.5^{\circ} \mathrm{C}$. She responded appropriately to pain but not to commands. She seemed not to acknowledge or recognise her family. She would intermittently give a startle reaction. Her serum sodium concentration was $130 \mathrm{mmol} / \mathrm{l}$ (normal range $136-145 \mathrm{mmol} / \mathrm{l}$ ) but the results of biochemical and haematological investigations were otherwise normal. Screening for psychoactive drugs detected 3,4-methylenedioxymethamphetamine and its metabolite 3,4-methylenedioxyamphetamine in urine but not plasma (limit of detection in plasma $0.01 \mathrm{mg} / \mathrm{l}$ ). Twelve hours later ( 54 hours after ingestion) she began to respond to commands and recovered fully.

CASE 2

A 17 year old woman collapsed a few hours after taking one capsule of 3,4-methylenedioxymethamphetamine. She had taken this drug once before without adverse effects. During the evening she had danced continuously and drunk about five litres of water. After collapsing she slept until the following afternoon, when she became restless, uncommunicative, and incontinent. That evening she was taken to hospital, where she was apparently conscious but poorly responsive to commands. At times she sat up and moved about spontaneously with a "wild eyed" look. She did not speak. She was afebrile and had widely dilated reactive pupils but no other abnormal signs. Her plasma sodium concentration was $118 \mathrm{mmol} / \mathrm{l}$ and magnesium concentration $0.64 \mathrm{mmol} / 1$ $(0.7-1.0 \mathrm{mmol} / \mathrm{l})$ and her plasma and urine osmolality were $247 \mathrm{mmol} / \mathrm{kg}(285-295)$ and $970 \mathrm{mmol} / \mathrm{kg}$ (38-1400) respectively. Other biochemical and haematological investigations gave normal results. An electrocardiogram showed a prolonged QT interval $(0.46 \mathrm{~s})$. Full toxicological screening showed only 3,4-methylenedioxymethamphetamine in plasma $(0.05 \mathrm{mg} / \mathrm{l})$ and 3,4-methylenedioxymethamphetamine and 3,4-methylenedioxyamphetamine in urine. Management was conservative. Eighteen hours after admission her pupil size was normal, as was an electrocardiogram. She began to communicate but remembered nothing of the previous 40 hours. Her subsequent recovery was uneventful.

\section{Comment}

Other than a brief report on a patient who became mute and semicatatonic for 72 hours after her regular monthly dose $(130 \mathrm{mg})$ of 3,4-methylenedioxymethamphetamine, ${ }^{2}$ we have found no other reports of catatonic stupor or of the syndrome of inappropriate antidiuretic hormone secretion after taking this drug. In our cases amounts reported to be ingested and the concentrations measured do not indicate large dosage and screening detected no other psychoactive drugs. Dilutional hyponatraemia may have been induced in the second case, by drinking five litres of water, but it does not explain why the kidneys did not respond by diuresis.

Transient psychological effects may follow ingestion of 3,4-methylenedioxymethamphetamine, and trained staff giving first aid at large "rave" parties encounter various medical and psychological problems. ${ }^{3}$ Our cases show that clinically important and unpredictable effects may occur.

Although tachycardia and hypertension induced by 3,4-methylenedioxymethamphetamine are fairly common, to our knowledge, a prolonged QTc interval has not been reported. It is a risk factor for ventricular tachycardia, ventricular fibrillation, and sudden death ${ }^{4}$ so might help to explain some of the reported deaths. ${ }^{5}$ Electrocardiographic monitoring is warranted in 3,4-methylenedioxymethamphetamine toxicity.

1 Henry JA, Jeffreys KJ, Dawling S. Toxicity and deaths from 3,4-methylenedioxymethamphetamine ("ecstasy"). Lancet 1992;340:384-7.

2 Siegel RK. MDMA non-medical use and intoxication. 7 Psychoactive Drugs 1986;18:349-54.

3 Chambers J, Guly H. The impact of a music festival on local health services. Health Trends 1991;23(3):122-3.

4 Algra A, Tijssen JGP, Roelandt RTC, Pool J, Lubsen J. QTc prolongation measured by standard 12-lead electrocardiography is an independent risk measured by standard 12-lead electrocardiography is an independent risk
factor for sudden death due to cardiac arrest. Circulation 1991;83:1888-94.

5 Dowling GP, McDonagh ET, Bost RO. "Eve" and "ecstasy": a report of five Dowling GP, McDonagh ET, Bost RO. "Eve" and "ecstasy": a report of five
deaths associated with the use of MDMA and MDEA. भAMA 1987;257: deaths assoc

(Accepted 22 fuly 1993) 